\title{
Quality of extracts from blueberry pomace by high hydrostatic pressure, ultrasonic, microwave and heating extraction: A comparison study
}

\author{
Haining Zhang ${ }^{1,2 *}$, William Tchabo ${ }^{2}$, Yongkun $\mathrm{Ma}^{2 *}$ \\ ${ }^{1}$ School of Food and Drug, Luoyang Normal University, Luoyang 471022, China, ${ }^{2}$ School of Food and Biological Engineering, Jiangsu \\ university Xuefu Road 301, Zhenjiang 212013, Jiangsu, P. R. China
}

\section{A B S T R A C T}

\begin{abstract}
The objective of this study was to compare the efficiency of high hydrostatic pressure, ultrasonic, microwave, and heat extraction techniques on the blueberry pomace extract characteristics. The results showed that the highest extraction yield of anthocyanins and total phenols were obtained by high hydrostatic pressure assisted extraction. The difference of extraction yield of anthocyanins was significant $(p<0.05)$ between high hydrostatic pressure assisted extraction and heating extraction. Furthermore, significant difference of total phenols extraction yield was obtained between high hydrostatic pressure assisted extraction and the other three extraction methods. The total color difference was significant for the four extraction methods. High hydrostatic pressure assisted extraction had the highest chroma and least browning index. Moreover, high hydrostatic pressure assisted extraction was found to have the highest hydroxyl radical scavenging activity. In summary, high hydrostatic pressure assisted extraction was revealed to be the suitable technique for phenolic extraction of blueberry pomace.
\end{abstract}

Keywords: Anthocyanins; Antioxidant activity; Ccolor

\section{INTRODUCTION}

A number of beneficial effects are attributed to anthocyanins, which is an important bioactive compound found in blueberries, including improving visual acuity, antioxidant, anticancer (Shim et al., 2012; Faria et al., 2010). There are many anthocyanins residues that remain after blueberries have been processed for juice, wine or other products (Lee, 2002; Khanal et al., 2010), the anthocyanins extracted from blueberry pomace is a potential source for natural colorants and nutraceuticals. Anthocyanins is sensitive to many factors, including $\mathrm{pH}$, metal ions, light, enzyme, oxygen (Zheng et al., 2003; Castañeda-Ovando et al., 2009) especially, it is unstable during heating. Traditional extraction method contained heating processing will degrade anthocyanins. Many researchers have demonstrated that the heat degradation of anthocyanins aggravates in many products along with the temperature rising (Brownmiller et al., 2008; Sarkis et al., 2013).
A suitable method of anthocyanins extraction is necessary, there are some researches on blueberry anthocyanins extraction by ultrasound (He et al., 2016), microwave (Zheng et al., 2013) and heating (Barnes et al., 2009).

In this years, high hydrostatic pressure (HHP) is recognized as a non-thermal and environment-friendly technology widely used in food industry. High hydrostatic pressure extraction (HHPE) as a technique was first reported by Shouqin et al (2004) is used for extraction active compound from plant materials. HHP can enhance the mass transfer, damage cell membrane, increase permeability, it had been successfully used for extraction carotenoid from tomato puree (Sánchez-Moreno et al., 2004), flavonoids from propolis (Shouqin et al., 2005), anthocyanins from grape skins (Corrales et al., 2009), catechins from green tea (Jun et al., 2010), bioactive compounds from Deodeok (He et al., 2011), anti-obesity substance from garlic (Joo et al., 2013).

\footnotetext{
*Corresponding authors:

Haining Zhang, School of Food and Drug, Luoyang Normal University, Luoyang 471022, China. E-mail: zhn19862006@163.com

Yongkun Ma, School of Food and Biological Engineering, Jiangsu university Xuefu Road 301, Zhenjiang 212013, Jiangsu, P. R. China.

E-mail: mayongkun@ujs.edu.cn
}

Received: 13 March 2017; Revised: 14 October 2017; Accepted: 15 October 2017; Published Online: 19 October 2017 
Their results indicated HHPE could improve yield, shorten time, and enhance biological activity. However, any study has been conducted on anthocyanins extraction of blueberry by HHPE.

Therefore, the aim of this study was to compare the differences in yield, color, browning index and antioxidant capacity of extracts, obtained from blueberry pomace by different methods such as HHPE, ultrasonic assisted extraction (UE), microwave assisted extraction (ME) and heating extraction (HE).

\section{MATERIALS AND METHODS}

\section{Plant material}

Blueberry pomace were obtained after blueberry wine fermentation, the fresh Rabbiteye blueberries (Vaccinium ashei Reade, Gardenblue) were picked from a plantation in Lishui District (China). Blueberries were broken using a presser, after enzymolysis $1.5 \mathrm{~h}$ at $35^{\circ} \mathrm{C}$, blueberries were fermented at $21^{\circ} \mathrm{C}$ for 7 days. The wine pomace was collected after squeezing and drying to a constant weight at $40^{\circ} \mathrm{C}$ in a hot-air drying oven. The dried pomace was powdered used a grinder. The powders were stored at $-20^{\circ} \mathrm{C}$ until used.

\section{Chemicals}

All chemicals used in the study were analytical grade and was purchased from Sinopharm Chemical Reagent Co., Ltd. (Shanghai, China).

\section{Anthocyanins extraction preparation}

Extraction were conducted by $5.00 \mathrm{~g}$ blueberry pomace in a $150 \mathrm{~mL}$ extraction solvent which contained $60 \%$ ethanol and $12 \mathrm{M} \mathrm{HCl}(\mathrm{V} / \mathrm{V}=99 / 1)$.

\section{Heating extraction}

Packaged samples in polythene bags were cooled immediately after incubated in a water bath at $60^{\circ} \mathrm{C}$ for $1 \mathrm{~h}$.

\section{Ultrasonic assisted extraction}

Packaged samples in polythene bags were extracted in a Ultrasonic bath equipment (Wuxi Fanbo Biological Engineering Co. Ltd, Wuxi, China) with ultrasonic power of $50 \mathrm{w} / \mathrm{L}$ water (the device power is $300 \mathrm{~W}, 6 \mathrm{~L}$ water in the treatment chamber) and ultrasonic frequency of $28 \mathrm{KHz}$ for $1 \mathrm{~h}$.

\section{Microwave assisted extraction}

Samples in a tub were extracted in a LG W900 microwave oven (Tianjin, China) with microwave power $360 \mathrm{~W}$ for 150s. The samples were cooled rapidly when extraction completed.

\section{High hydrostatic pressure assisted extraction}

Packaged samples in polythene bags were pressed under $500 \mathrm{Mpa}$ for $3 \mathrm{~min}$ at room temperature using a high hydrostatic pressure machine (Intelligent Super High Pressure Food Processing Device, Jiangsu University, China).

\section{Total anthocyanins extraction}

The total anthocyanins extraction was carried out UE. The extraction solution was filtered using vacuum filtration equipment (RE-2000B, Shanghai Yarong Biochemical Instrument Factory, China), residue was extracted again using the extraction solvent until the absorbance of the extraction solution was less than 0.005 . The filtrate was merged and used to determine the content of anthocyanins and total phenols.

The extraction yield of Anthocyanins and total phenols The anthocyanins content of extracts was determined according to Giusti and Rrolstad, 2001. The total phenols content was determined as described by Sellappan et al., (2002). The extraction yield of anthocyanins and total phenols were calculated as follows:

Extraction yield $=$ the content of different extraction method/the content of total extraction

\section{Sample determination preparation}

The extracted sample was prepared by the method of Prasad et al (2010) with some modifications. $100 \mathrm{~mL}$ extraction solution was filtered using vacuum filtration equipment. The filtrate was evaporated to remove the extraction solvent by a rotary evaporator under vacuum at $40^{\circ} \mathrm{C}$. The concentration solution was dried using a vacuum freeze dryer, $0.1 \mathrm{~g}$ dried extracts was diluted with sodium citrate buffer (pH3.0, 0.1M) to $100 \mathrm{~mL}$. The sample solution was stored at $4^{\circ} \mathrm{C}$ until used.

\section{Browning Index (BI)}

The browning index of blueberry extracts was determined according to Buglione and Lozano (2002).

\section{Color measurements}

A DC-P3 colorimeter (Beijing Xingguang ColorMeasurement Instrument Company Ltd., China) was used to determine the lightness $\left(\mathrm{L}^{*}\right)$, Hue $(\mathrm{H})$, Chroma $(\mathrm{C})$ and total color difference $(\Delta \mathrm{E})$.

\section{Hydroxyl radical $(\cdot \mathrm{OH})$ scavenging acitivity}

The antioxidant activity was determined as described by Wang et al., 2008.

\section{Statistical analysis}

All experiments were conducted in triplicate. The statistical analyses were performed using software Excel 2003 and 
SPSS 17.0. The Duncan's test was used to determine the differences of means at the $5 \%$ confidence level.

\section{RESULTS AND DISCUSSION}

In this research total anthocyanins content reached $208.53 \pm 20.38(\mathrm{mg} / 100 \mathrm{~g}$ sample powders $)$ and total phenols content reached $2298.99 \pm 16.99 \mathrm{mg}$ gallic acid equivalents/100 $\mathrm{g}$ of sample powders. The extraction yield of anthocyanins and total phenols by different extraction methods were showed in Fig. 1 and Table 1. HHPE had the highest extraction yield of anthocyanins, but the difference between HHPE and HE was significant $(p<0.05)$. Meanwhile, the highest extraction yield of total phenols was obtained by HHPE, the difference was significant between HHPE and the other three extraction methods. The extraction yield of total phenols obtained by UE was higher than HE and ME, but the difference was not significant.

The result was similar to Corrales et al., 2009 who reported that the total anthocyanins content extracted from grape pomace using HHPE was higher than HE and UE, and the difference was significant.

The color parameters is an important factor on the quality of products, the color parameters and browning index of extracts by different extraction methods were measured and

Table 1: Extraction yield of anthocyanins and total phenols by four extraction methods

\begin{tabular}{lcc}
\hline & $\begin{array}{c}\text { Anthocyanins extraction } \\
\text { yield }\end{array}$ & $\begin{array}{c}\text { Total phenols extraction } \\
\text { yield }\end{array}$ \\
\hline HE & $32.43 \pm 1.91^{\mathrm{a}}$ & $53.18 \pm 3.61^{\mathrm{a}}$ \\
$\mathrm{ME}$ & $36.76 \pm 5.44^{\mathrm{ab}}$ & $55.07 \pm 3.32^{\mathrm{a}}$ \\
$\mathrm{UE}$ & $38.44 \pm 6.54^{\mathrm{ab}}$ & $57.35 \pm 7.68^{\mathrm{a}}$ \\
$\mathrm{HHPE}$ & $44.2 \pm 5.76^{\mathrm{b}}$ & $70.26 \pm 5.63^{\mathrm{b}}$
\end{tabular}

The same letter in the same column indicates that the difference of the means is not significant at the level 0.05

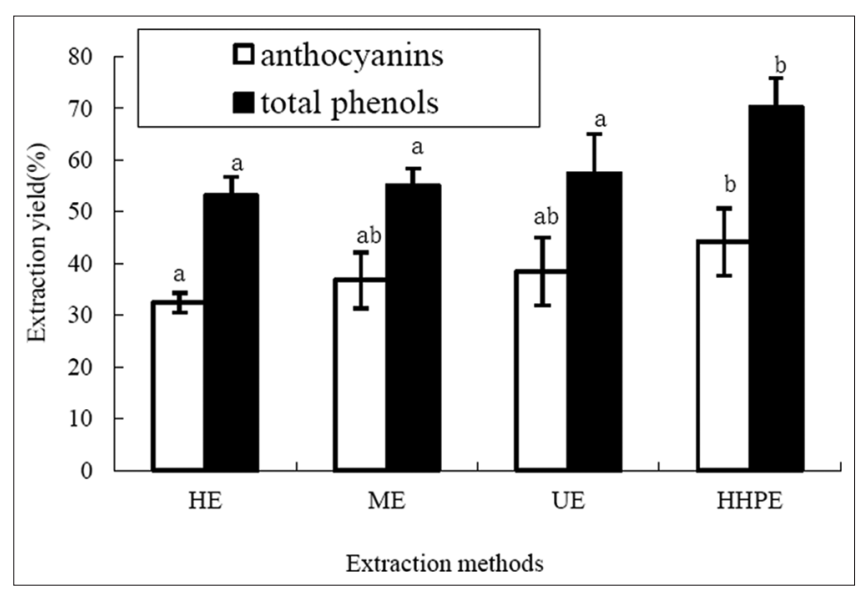

Fig 1. Extraction yield of anthocyanins and total phenols by four extraction methods showed in Table 2. HHPE treated sample had the maximum $\mathrm{L}^{*}$ and $\mathrm{H}$, but the difference was not significant during four extraction methods. Significant difference of $\Delta \mathrm{E}$ and $\mathrm{C}$ were observed in Table 2, HHPE had the highest $\triangle \mathrm{E}$ and $\mathrm{C}$. This may be due to the difference on anthocyanins content, anthocyanins was the main color substance in fruits (He and Giusti, 2010), the most anthocyanins was obtained by HHPE. Hyoung reported $\Delta \mathrm{E}>2$ was considered a noticeable difference in the visual perception of the samples (Lee and Coates, 2003), therefore, the noticeable difference was likely to be exist between HHPE sample and HE sample which was accordance with the difference of anthocyanins yield. Wrolstad et al. (2005) considered the $\mathrm{C}$ increased with pigment concentration increasing within certain limits (Wrolstad et al., 2005), the results also showed some level of positive correlation between $\mathrm{C}$ and the content of anthocyanins, the $\mathrm{C}$ reflected the content of anthocyanins to some extent.

ME had the highest BI, and HHPE had the least, the difference was significant between HHPE and the other three methods. BI was related to the extraction temperature and extraction time, higher $\mathrm{BI}$ was obtained by $\mathrm{HE}$ and $\mathrm{ME}$ because $\mathrm{HE}$ had the longest extraction time $\left(40^{\circ} \mathrm{C} / 1 \mathrm{~h}\right)$ and $\mathrm{ME}$ had the highest extraction temperature(exceed $60^{\circ} \mathrm{C}$ ), nevertheless, HHPE had the least BI with ambient temperature extraction of $3 \mathrm{~min}$. This may be because the high temperature (heating and microwave) accelerated anthocyanins degradation and Maillard reaction, which enhanced BI. However, the non-significant of HHP treatment under $600 \mathrm{Mpa}$ on anthocyanins degradation or Maillard reaction has been reported by Torres et al. (2011) and Schwarzenbolz et al. (2002).

- $\mathrm{OH}$ scavenging capacity of an extracts is directly related to its antioxidant activity (Kim et al., 2011). HHPE revealed a higher $\cdot \mathrm{OH}$ scavenging activity (Fig. 2) than $\mathrm{HE}, \mathrm{ME}$ and

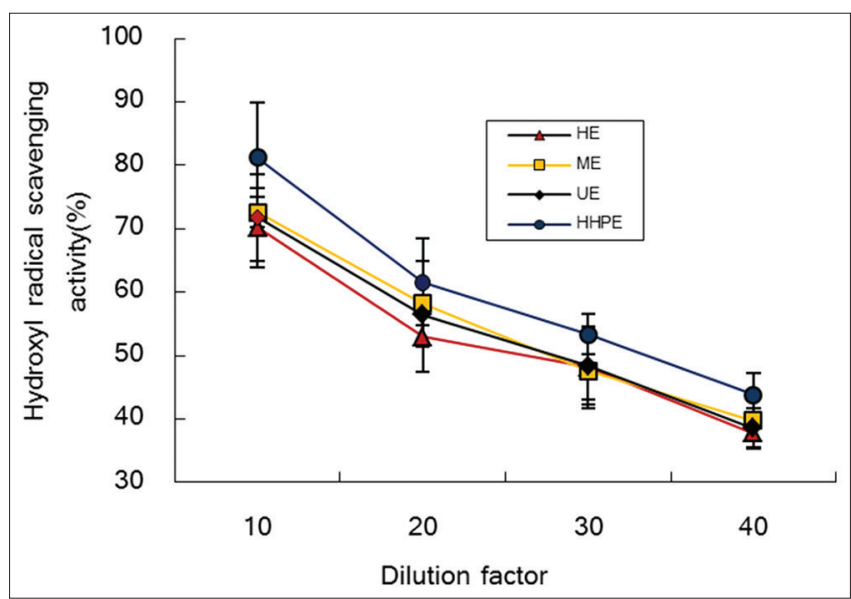

Fig 2. Hydroxyl radical scavenging activity of extracts by four extraction methods. 
Table 2: The color quality and browning index of extracts by four extraction methods

\begin{tabular}{lccccc}
\hline & \multicolumn{1}{c}{$\mathbf{L}^{*}$} & $\Delta \mathrm{E}$ & $\mathbf{H}$ & $\mathbf{C}$ & $\mathbf{B}$ \\
\hline HE & $28.86 \pm 1.11^{\mathrm{a}}$ & --- & $23.42 \pm 1.24^{\mathrm{a}}$ & $43.42 \pm 0.63^{\mathrm{a}}$ & $1.06 \pm 0.01^{\mathrm{bc}}$ \\
ME & $28.65 \pm 0.18^{\mathrm{a}}$ & $1.45 \pm 0.52^{\mathrm{b}}$ & $23.95 \pm 1.06^{\mathrm{a}}$ & $43.78 \pm 0.63^{\mathrm{a}}$ & $1.08 \pm 0.01^{\mathrm{c}}$ \\
UE & $28.86 \pm 1.27^{\mathrm{a}}$ & $0.69 \pm 0.16^{\mathrm{a}}$ & $23.22 \pm 1.26^{\mathrm{a}}$ & $43.57 \pm 0.67^{\mathrm{a}}$ & $1.04 \pm 0.02^{\mathrm{b}}$ \\
HHPE & $30.20 \pm 1.06^{\mathrm{a}}$ & $2.95 \pm 0.34^{\mathrm{c}}$ & $24.23 \pm 1.31^{\mathrm{a}}$ & $45.85 \pm 0.52^{\mathrm{b}}$ & $0.99 \pm 0.01^{\mathrm{a}}$ \\
\hline
\end{tabular}

The same letter in the same column indicates that the difference of the means is not significant at the level 0.05 , Lightness $\left(\mathrm{L}^{*}\right)$, Total color difference $(\Delta \mathrm{E})$, Hue $(\mathrm{H})$, Chroma (C), Browning index (BI)

UE, it indicated more antioxidant compounds extracted by HHPE because HHP could enhance mass transfer, increase cell permeability and accelerate the movement of water and metabolites. It was in accordance with the extraction yield of anthocyanins and total phenols. The results were similar with some researchers who found the antioxidant activity from green tea, aloe vera, strawberry and blackberry improved under HHPE (Xi et al., 2011; Vega-Gálvez et al., 2011; Patras et al., 2009).

\section{CONCLUSION}

Four extraction methods were used to extract active compounds from blueberry pomace. Compared to HE, ME and UE, HHPE revealed a good effect on blueberry pomace extraction, including higher extraction yield, better color quality, shorter extraction time and higher hydroxyl radical scavenging activity.

\section{ACKNOWLEDGEMENT}

The work was supported by Graduate innovative fund of Jiangsu Province ordinary university of China (NO. CXZZ13_0696)

\section{Authors' Contributions}

Yongkun Ma conceived and designed the study, Haining Zhang performed the experiments and analyzed the data, William Tchabo reviewed and edited the manuscript.

\section{REFERENCES}

Barnes, J. S., H. P. Nguyen, S. Shen and K. A. Schug. 2009. General method for extraction of blueberry anthocyanins and identification using high performance liquid chromatography-electrospray ionization-ion trap-time of flight-mass spectrometry[J]. J. Chromatogr. A. 1216(23): 4728-4735.

Brownmiller, C., L. R. Howard and R. L. Prior. 2008. Processing and storage effects on monomeric anthocyanins, percent polymeric color, and antioxidant capacity of processed blueberry products. J. Food Sci. 73(5): H72-H79.

Buglione, M. and J. Lozano. 2002. Nonenzymatic Browning and Chemical Changes During Grape Juice Storage. J. Food Sci. 67(4): 1538-1543.

Castañeda-Ovando, A., M. de Lourdes. Pacheco-Hernández, M. E. Páez-Hernández, J. A. Rodríguez and C. A. Galán-Vidal. 2009.
Chemical studies of anthocyanins: A review. Food Chem. 113(4): 859-871.

Corrales, M., A. F. García, P. Butz and B. Tauscher. 2009. Extraction of anthocyanin from grape skins assisted by high hydrostatic pressure. J. Food Eng. 90(4): 415-421.

Faria, A., D. Pestana, D. Teixeira, V. Freitas, N. Mateus and C. Calhau. 2010. Blueberry anthocyanin's and pyruvic acid adducts: Anticancer properties in breast cancer cell lines. Phytother. Res. 24(12): 1862-1869.

Giusti, M. M. and R. E. Rrolstad. 2001. Characterization and measurement of anthocyanin's by UV-visible spectroscopy. Current Protocols in Food Analytical Chemistry, John Wiley \& Sons, Inc., New York, ppF1.2.1-F1.2.13.

He, B., L. L. Zhang, X. Y. Yue, J. Liang, J. Jiang, X. L. Gao and P. X. Yue. 2016. Optimization of ultrasound-assisted extraction of phenolic compounds and anthocyanin's from blueberry (Vaccinium ashei) wine pomace[J]. Food Chem. 204: 70-76.

He, J. and M. M. Giusti. 2010. Anthocyanin's: Natural colorants with health-promoting properties. Annu. Rev. Food Sci. Technol. 1: 163-187.

He, X., W. B. Yoon, S. J. Park, D. S. Park and J. Ahn. 2011. Effects of pressure level and processing time on the extraction of total phenols, flavonoids, and phenolic acids from Deodeok (Codonopsis lanceolata). Food Sci. Biotechnol. 20(2): 499-505.

Joo, H., C. T. Kim, I. H. Kim and Y. Kim. 2013. Anti-obesity effects of hot water extract and high hydrostatic pressure extract of garlic in rats fed a high-fat diet. Food Chem. Toxicol. 55: 100-105.

Jun, X., Z. Shuo, L. Bingbing, Z. Rui, L. Ye, S. Deji and Z. Guofeng. 2010. Separation of major catechins from green tea by ultrahigh pressure extraction. Int. J. Pharm. 386(1-2): 229-231.

Khanal, R. C., L. R. Howard and R. L. Prior. 2010. Effect of heating on the stability of grape and blueberry pomace procyanidins and total anthocyanins. Food Res. Int. 43(5): 1464-1469.

Kim, I. S., M. Yang, O. H. Lee and S. N. Kang. 2011. The antioxidant activity and the bioactive compound content of Stevia rebaudiana water extracts. LWT Food Sci. Technol. 44(5): 1328-1332.

Lee, H. S. and G. A. Coates. 2003. Effect of thermal pasteurization on Valencia orange juice color and pigments. LWT Food Sci. Technol. 36: 153-156.

Lee, J., R. W. Durst and R. E. Wrolstad. 2002. Impact of Juice Processing on Blueberry Anthocyanin's and Polyphenolics: Comparison of Two Pretreatments. J. Food Sci. 67: 1660-1667.

Patras, A., N. P. Brunton, S. Da Pieve and F. Butler. 2009. Impact of high pressure processing on total antioxidant activity, phenolic, ascorbic acid, anthocyanin content and colour of strawberry and blackberry purées. Innov. Food Sci. Emerg. 10(3): 308-313.

Prasad, K.N., B. Yang, M. Zhao, J. Sun, X. Wei and Y. Jiang. 2010. Effects of high pressure or ultrasonic treatment on extraction yield and antioxidant activity of pericarp tissues of longan fruit. J. Food Biochem. 34(4): 838-855.

Sánchez-Moreno, C., L. Plaza, B. Ancos and M. P. Cano. 2004. Effect of combined treatments of high-pressure and natural additives 
on carotenoid extractability and antioxidant activity of tomato puree. Eur Food Res. Technol. 219: 151-160.

Sarkis, J. R., D. P. Jaeschke, I. C. Tessaro and L. D Marczak. 2013. Effects of ohmic and conventional heating on anthocyanin degradation during the processing of blueberry pulp. LWT Food Sci. Technol. 51(1): 79-85.

Schwarzenbolz, U., H. Klostemeyer and T. Henle. 2002. Maillard reaction under high hydrostatic pressure studies on the formation of protein-bound amino acid derivatives. International Congress Series, 1245: 223-227.

Sellappan, S., C. C. Akoh and G. Krewer. 2002. Phenolic compounds and antioxidant capacity of Georgia-grown blueberries and blackberries. J. Agric. Food Chem. 50: 2432-2438.

Shim, S. H., J. M. Kim, C. Y. Choi, C. Y. Kim and K. H. Park. 2012. Ginkgo biloba extract and bilberry anthocyanin's improve visual function in patients with normal tension glaucoma. J. Med. Food. 15(9): 818-823.

Shouqin, Z., X. Jun and W. Changzheng. 2005. High hydrostatic pressure extraction of flavonoids from propolis. J. Chem. Technol. Biot. 80(1): 50-54.

Shouqin, Z., Z. Junjie and W. Changzhen. 2004. Novel high pressure extraction technology. Int. J. Pharm. 278(2): 471-474.

Torres, B., B. K. Tiwari, A. Patras, P. J. Cullen, N. Brunton and C.
P. O'Donnell. 2011. Stability of anthocyanin's and ascorbic acid of high pressure processed blood orange juice during storage. Innov. Food Sci. Emerg. 12(2): 93-97.

Vega-Gálvez, A., E. Uribe, M. Perez, G. Tabilo-Munizaga, J. Vergara, P. Garcia-Segovia, E. Lara and K. D. Scala. 2011. Effect of high hydrostatic pressure pretreatment on drying kinetics, antioxidant activity, firmness and microstructure of Aloe vera (Aloe barbadensis Miller) gel. LWT Food Sci. Technol. 44(2): 384-391.

Wang, H., X. D. Gao, G. C. Zhou, L. Cai and W. B. Yao. 2008. In vitro and in vivo antioxidant activity of aqueous extract from Choerospondias axillaris fruit. Food Chem. 106(3): 888-895.

Wrolstad, R. E., R. W. Durst and J. Lee. 2005. Tracking color and pigment changes in anthocyanin products. Trends. Food Sci. Technol. 16(9): 423-428.

Xi, J., D. Shen., Y. Li and R. Zhang. 2011. Ultrahigh pressure extraction as a tool to improve the antioxidant activities of green tea extracts. Food Res. Int. 44(9): 2783-2787.

Zheng, X., X. Xu, C. Liu, Y. Sun, Z. Lin and H. Liu. 2013. Extraction characteristics and optimal parameters of anthocyanin from blueberry powder under microwave-assisted extraction conditions [J]. Sep. Purif. Technol. 104: 17-25.

Zheng, Y., C. Y. Wang, S. Y. Wang and W. Zheng. 2003. Effect of HighOxygen Atmospheres on Blueberry Phenolics, Anthocyanins, and Antioxidant Capacity. J. Agric. Food Chem. 51: 7162-7169. 